www.dnr.state.mn.us/waters/programs/gw

section/springs/dtr-list.html. Accessed July 2019.

Minnesota Department of Natural Resources b, Minnesota Spring Inventory, https://files.dnr.state. mn.us/waters/groundwater_section/mapping/msi/ MSI_GuideDoc.pdf. Accessed July 2019

Natural Resources Conservation Service, Soil Survey Geographic Database (SSURGO), U.S. Department of Agriculture, data for Houston County, Minnesota.

Runkel AC, Steenberg JR, Tipping RG, Retzler AJ. 2013. Geologic controls on groundwater and surface water flow in southeastern Minnesota and its impact on nitrate concentrations in streams. Minnesota Geological Survey Open File Report 14-2. $70 \mathrm{p}$

Runkel AC, Tipping RG, Alexander EC, Jr., Green JA, Mossler JH, Alexander SC. 2003. Hydrogeology of the Paleozoic bedrock in southeastern Minnesota. MGS Report of Investigations 61, 105 p., 1 map in pocket.

Runkel, AC, Tipping RG, Meyer JR, Steenberg JR, Retzler AJ, Parker BL, Green JA, Barry JD, Jones PM. 2018. A multidisciplinary based conceptual model of a fractured bedrock aquitard: improved prediction of aquitard integrity. Hydrogeology Journal, v. 26, n. 7. p. 2133-2159.

Steenberg JR. 2014. Bedrock Geology, plate 2, Geologic Atlas of Houston County, Minnesota, Minnesota Geological Survey County Atlas C-33, Part A.

Surber T. 1920. Streams of Southeastern Minnesota, Surveys and Investigations, Minnesota Game \& Fish Department.

Tipping RG, Green JA, Alexander EC Jr. 2001. Karst features, plate 5, Geologic atlas of Wabasha County, Minnesota. Minnesota Geological Survey County Atlas C-14, part A.

Tipping, R.G., Rantala, M., Alexander, E.C. Jr., Gao, Y., Green, J.A., 2015, History and future of the Minnesota karst feature database in Doctor, D., Land, L., Stephenson, J.B. (eds.) Sinkholes and the engineering and environmental Aspects of Karst: Proceedings of the 14th Multidisciplinary Conference, October 5-9, 2015, Rochester,
Minnesota, National Cave and Karst Research Institute Symposium 5, p. 263-270. 


\title{
A PROCEDURE FOR EVALUATING LAND DISTURBANCES AT THE SITE LEVEL IN FORESTED KARST AREAS OF BRITISH COLUMBIA, CANADA
}

\author{
Tim Stokes \\ Terra Firma Geoscience \\ 1480 Sherwood Drive, Nanaimo,British Columbia, Canada,V9T 1G7.tstokes@island.net \\ Earth Science Department \\ Vancouver Island University, 900 Fifth St, Nanaimo, British Columbia,V9R 5S5, Canada.tim.stokes@viu.ca
}

\begin{abstract}
Land disturbances in karst can result in considerable adverse ecological impacts if the nature and characteristics of karst systems and processes are not considered. This is particularly the case for the well-developed and forested karst of coastal British Columbia (BC). Industrial forestry activities in the region typically comprise of building logging roads, harvest openings (or cut blocks) and post-harvest silviculture treatments. In conjunction with the BC Ministry of Forests, Lands, Natural Resource Operations and Rural Development, an evaluation procedure has been developed to assess whether current forestry practices are adequately protecting and maintaining karst surface and subsurface system elements at the site-level. The basic approach is to assess the environmental status of surface karst feature samples using seven core disturbance indicator questions related to: a) tree removal, b) windthrow, c) introduced materials, d) forest floor/soil/bedrock disturbance, e) burning, f) shade alteration, and g) changes in lower plant community. From these indicators it is then possible to report on the disturbances observed at the surface karst features within the sample area. A series of questions are then asked with respect to forest practices and management, with the aim of continual improvement. Additional information can also be collected on retention areas that surround surface karst features, the broader karst landscape, and cave infiltration areas. The evaluation procedure has been complied into a digital checklist for use in the field with an Apple iPad, allowing for ease of data collection, storage and transfer. This procedure could potentially be modified to collect disturbance data for other land use development or resource activities that occur on karst.
\end{abstract}

\section{Introduction}

Human-related land disturbances in karst areas have been well documented in relation to karst system elements such as soil, the subsurface karst environments including caves, karst biota and karst aquifers (Ford, 1993). Overall it is recognized that karst landscapes are more sensitive to disturbance, as compared to others, primarily due to the open connections between surface and subsurface karst, the underground drainage system of karst, and its associated ecosystem (Watson et al, 1997). The principal types of disturbances that can occur at the surface include vegetation removal, soil changes, and the alteration of water quality and flow. These disturbances can result in a range of impacts and effects on the processes and functions of the karst system such as: loss of soil, deterioration of water quality, degradation of ecosystems and landform destruction (Williams, 1993).

The goal of this paper is to outline some of the concepts used in developing a procedure for evaluating disturbance to forested karst areas in British Columbia (BC) at the site level, where the focus is on disturbances that occur due to recent forestry activities within a cutblock. (A cutblock is typically an area of 5 to 40 ha that has been designated for forestry activities and includes a combination of clear cuts with trees removed, forest roads and treed reserves; see Figure 1). The karst evaluation procedure has been developed for the Forest and Range Evaluation Program (FREP) in conjunction with the BC Ministry of Forest, Lands, Natural Resource Operations and Rural Development (FLNRORD) and is intended to report on the status of karst resources and to aid in the improvement of forest practices. The procedure is constrained by a number of factors including: 1) it should be simple enough so that it can be carried out by a forest resource assessor (who is not necessarily a karst special- 


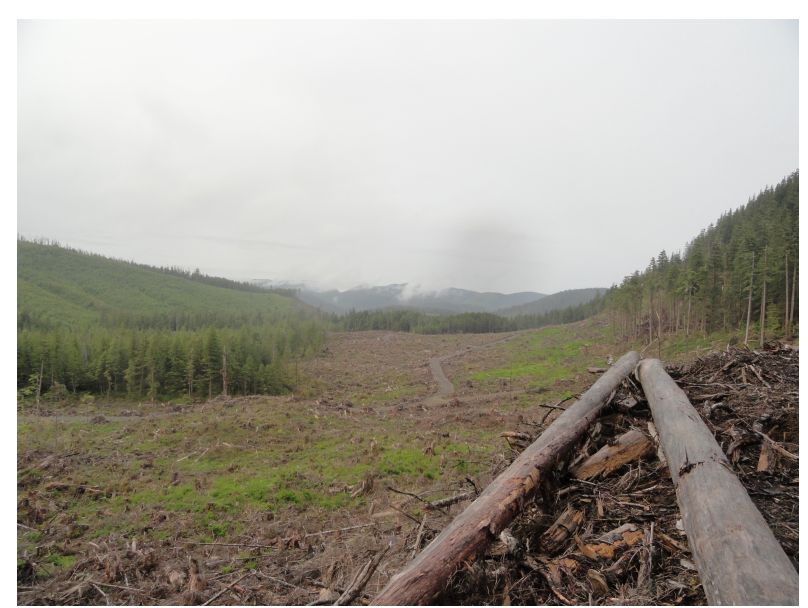

Figure 1. Forestry activities in a karst area of northwest Vancouver Island with a clearcut and forest road in centre of image. Yarding debris pile in foreground on edge of landing.

ist), 2) it should be a routine method based on direct field observations, 3) at least one cut block area should be assessed in a day, 4) it does not require any subsurface investigations, and 5) the results should be representative and reproducible.

For the purposes of this paper, the term 'disturbance' is primarily considered as the physical actions imposed on karst by recent forestry activities. Natural events such as tree overturning (windthrow), landslides, or biological infestations can also be disturbances, and likewise past disturbance can result from previous forestry activities. It is generally understood that these disturbances result in impacts and changes to the natural physical, chemical and biological functions of karst (beyond the range of natural variability) and include effects such as: increased runoff, increased sediment erosion and movement, and the alteration and/or impoverishment of the ecology (Williams, 1993).

Where possible karst terminology and karst management concepts outlined in the Karst Management Handbook for British Columbia (BC Ministry of Forests, 2003) and the Karst Inventory Standards and Vulnerability Assessment Procedures for British Columbia, version 2.0 (Resources Information Standards Committee, 2003) have been used in the development of the evaluation procedure.

\section{Background}

Considerable research and assessment has been completed worldwide in the examination of land disturbance on karst. Most of this work has been done at a regional or landscape level (1:50,000 scale or greater) and covers a wide range of disturbances such as caused by agriculture, quarrying, mining, engineering and urban development projects (van Beynen, 2011). Some disturbance evaluations in karst areas have focused on specific karst environments or attributes such as karst aquifers and cave fauna (Drew, 1996; James, 1993)

A holistic approach to evaluating karst disturbances was adopted by van Beynen and Townsend (2001). They used five categories (geomorphology, atmosphere, hydrology, biota and surface practices) and a total of 33 associated indicator attributes to measure and compare disturbances on karst landscapes. The resultant numerical based Karst Disturbance Index (KDI) was applied with variations to several karst regions of the world including west Florida, Italy, Sardinia, Spain and Puerto Rico (De Waele, 2009; North et al., 2009; Porter et al., 2016; Angulo, 2013; and van Beynen, 2011).

More specific studies have examined disturbances to surface vegetation and the effects on the karst. For example, vegetation removal and associated soil loss on karst in China has led to its transformation into a 'rocky karst landscape' (Huntoon, 1992). Jiang et al. (2014) provided a detailed summary of these issues and gave estimates for the recovery times for soils on karst, plus outlined ways in which restoration could occur. Another example of rocky desertification due to vegetation and forest cover loss has been reported in the Dinaric karst of the Mediterranean (Kranjc, 2012). Numerous other examples of similar rocky karst landscape change following vegetation removal around the world include such places as: Haiti (Williams, 2003), Belize (Day, 1996), Mexico, Indonesia (Sunkar, 2008) and Barbados.

Examples of disturbances on temperate forest karst areas following timber harvesting and associated forestry activities are fewer but can found be in New Zealand, Tasmania, Europe and southeast Alaska (Ford and Williams, 2007). One of best examples is from southeast Alaska and the Tongass National Forest, where Baichtal and Swanston (1996) outlined the intricate connection of forests to karst landscapes and described the impacts of 
past timber harvesting including increased run-off and soil loss, sediment and debris transfer into the subsurface, as well as slow tree regeneration. A more recent intensive study was completed in the forested karst of the French sub-alps where monitoring of the physical and chemical properties of drip waters was carried out in a cave before and after timber harvesting (Tissier et al., 2013).

Karst and potential karst area underlie about $10 \%$ of British Columbia (Figure 2) and occur in a range of different geomorphic settings from alpine, interior plateau to the west coast (Stokes and Griffiths, 2019). Most of the temperate forested karst occurs along the west coast of BC on Vancouver Island, Haida Gwai and the Mid/ North Coast, where the tree cover is typically comprised of western hemlock, western red cedar, Douglas fir and Sitka spruce (Figure 3). Research on disturbances to forested karst in these areas is limited. However, research completed by Harding and Ford (1993) in northern Vancouver Island compared clearcut (and mostly burned) karst areas to those underlain volcanic bedrock and identified a significant decrease in the depth of soil, an increase exposed bare rock and a low basal area for tree regeneration at the karst sites. The Forest Practices Board of $\mathrm{BC}$ has produced two reports on karst. The first examined damage to karst caused by logging and road building in an area of sinking streams and karst features on Haida Gwaii (Forest Practices Board, 2007).

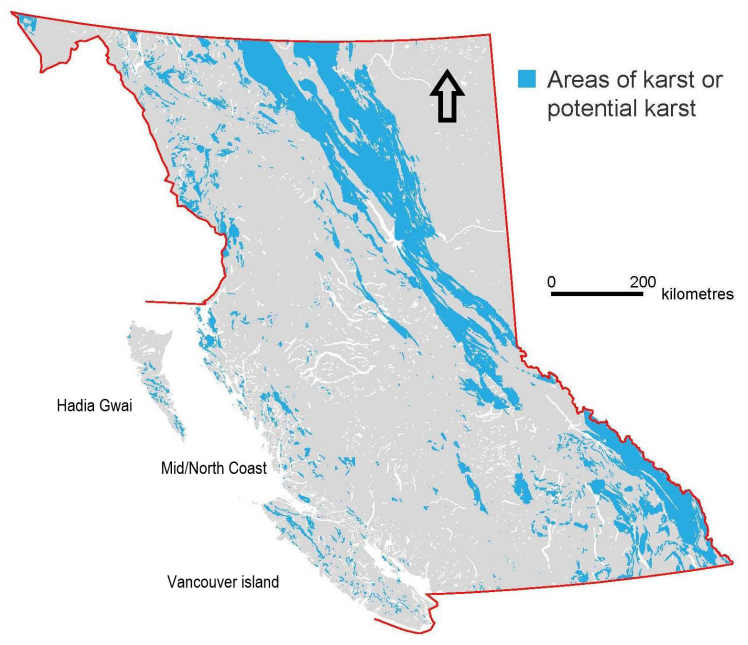

Figure 2. Distribution of carbonate bedrock and potential karst in $\mathrm{BC}$ along with the location of Vancouver Island, Haida Gwai and Mid/North Coast (adapted from Stokes and Griffiths, 2019)
The second was a special investigation report on the management of karst resources on northern Vancouver Island, which concluded that out of 128 karst features examined no caves or significant surface karst features had been 'damaged or rendered ineffective by forestry activities'(Forest Practices Board, 2014). However, this report did not provide the data or a clear rationale supporting this finding. A recent evaluation of surface karst feature data from northern Vancouver Island (Stokes, 2017) found that the surface karst features surrounded by forested retention areas typically had fewer disturbances, and that carefully designed retention areas were likely needed to limit post-harvest windthrow above natural rates.

\section{Methodology}

The FREP karst evaluation procedure is designed at the site or cutblock level so that it can be readily used to provide advice and improvements to current forest practices. At the site level the most obvious evidence for karst are the micro-, meso- to macro-scale surface karst features (e.g., from fine karren structures on bedrock surfaces, karst sinkholes to large 100's m -scale closed karst depressions). The focus of the FREP procedure is designed around the mesoscale surface karst features as they can be readily identified, sampled and measured. These mesoscale surface karst features are important sub-components of the greater karst system (physically,

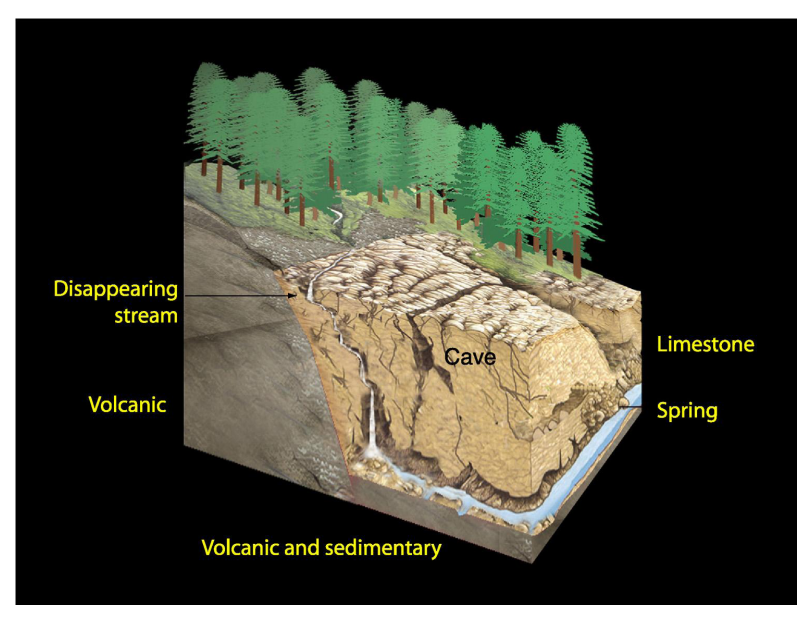

Figure 3. Forest covered karst of British Columbia and the three-dimensional karst landscape (from Stokes and Griffiths, 2019) 
biologically and hydrologically), and can also be broadly correlated to karst development - whereby the greater the number and density of the surface karst features, the more developed the karst site, and likewise the better the connection between the surface and subsurface elements of the karst system.

The FREP karst evaluation procedure is built on the premise that careful management of mesoscale surface karst features such as karst sinkholes (dolines), sinking streams, karst springs, cave entrances and other features will help to protect and maintain the associated karst system. The procedure at the 'Basic Level' focusses on evaluating the observable biophysical disturbances at these surface karst features using seven core disturbance indicators (Figure 4). Cave information is also collected at the 'Basic Level' to confirm the presence of caves and record whether they have been appropriately mapped and also if cave infiltration areas have been delineated
(Figure 4). 'Advanced Options' of the procedure can be used if necessary to examine aspects of the broader karst landscape (a combination of soils, epikarst and surface karst features), as well the ground surface above caves (cave infiltration area), and treed retention areas that surround surface karst features.

The FREP karst evaluation process and procedures can be broken down into a series of steps as follows:

1. Identification of a Site for Evaluation - The first step is to identify the site for sampling, which should include a cutblock where recent timber harvesting and road construction have occurred. In most cases clear-cutting is the main harvest method, either using ground-based or cable yarding equipment. Forest road construction is used for machine access and tree transport equipment and includes the development of small quarries/borrow

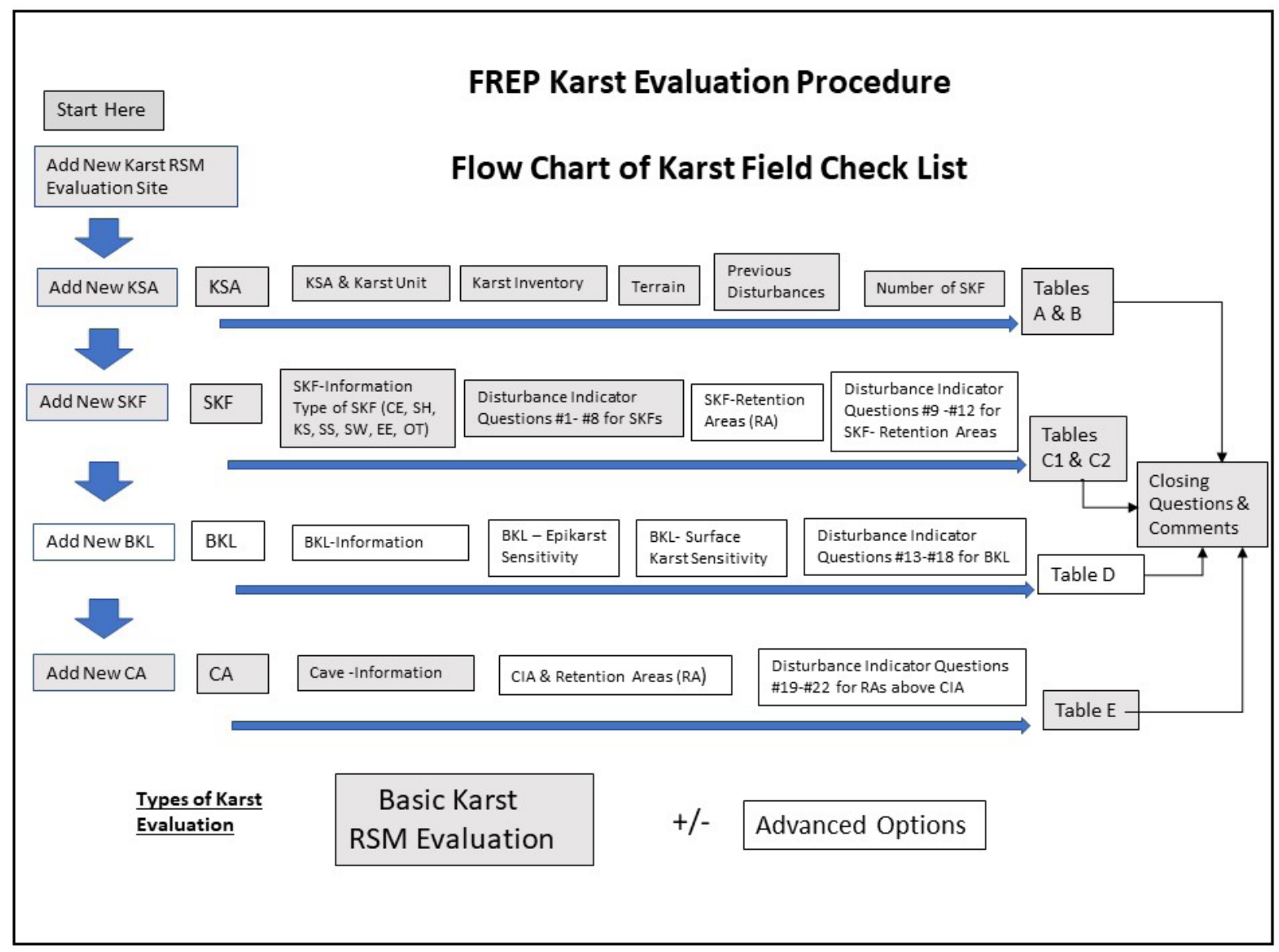

Figure 4. Flow chart of the FREP Karst Evaluation Procedure with the Basic Level and 'Advanced Options'. 
pits and landing areas. Treed retention areas or reserves are typically left in the centre or along the edges of cutblocks for various reasons (e.g., wildlife trees, individual surface karst features or clusters of surface karst features; see Figure 5). Cutblocks 1-5 years old and mostly underlain by karst bedrock are preferred for the evaluation procedure. Potential cutblocks can be identified using $\mathrm{BC}$ 's digital karst inventory data available through various web portals (i.e., iMapBC) which identify karst potential polygons delineated at 1:250,000-scale. Usually, some level of random selection of evaluation sample sites is carried out. Confirmation that the cutblocks contain karst resources can also come from forest licensees, where site plans and/or karst assessment reports have typically been completed for cutblocks.

2. Delimiting Karst Sampling Areas - Once a site has been selected for sampling it is then possible to either sample all surface karst features in the site (cutblock) or to sub-sample part of a site. In either case a karst sampling area is defined that includes harvested areas underlain by karst, nearby adjacent non-karst (where sinking streams may occur), and treed retention areas that occur internal or external to the cutbock. The size of the karst sample area selected can vary depending on the terrain and site conditions, but it should be 5 to 20 ha, so that it can be covered in a single day's field work

3. Selection and Sampling Surface Karst Features - Prior to the field visit, office work is required

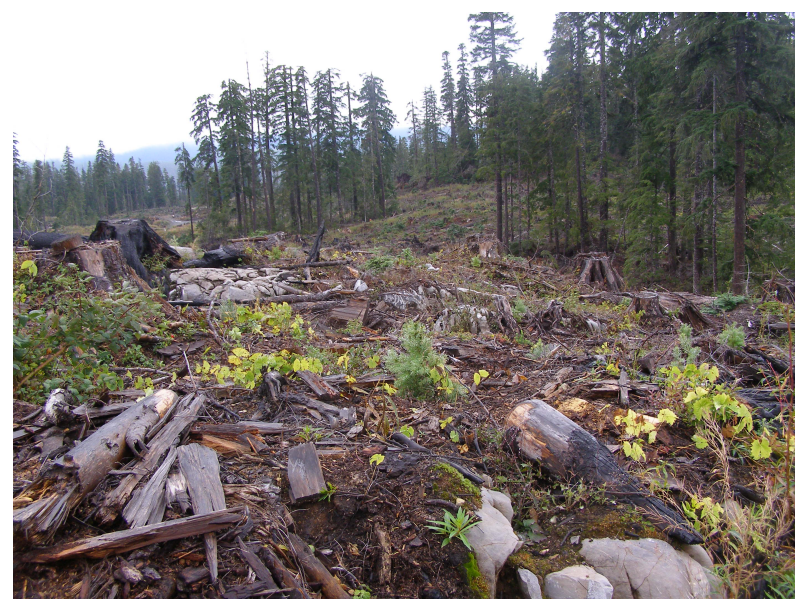

Figure 5. A recently harvested cutblock on karst with treed retention areas surrounding surface karst features. Exposed epikarst in foreground and middle of image, plus evidence of burning. to compile all known information about karst or potential karst in the sample area, and to develop a detailed field plan for the evaluation procedure. The locations of the known surface karst features are plotted onto a working map and a tentative walking route planned for the field work. Time may not permit sampling of all features, so a careful selection process is required to ensure that the variety of features ultimately sampled is representative of the site, and that some level of randomness is applied. Features may occur as individual 'feature types' such as a sinkhole or a large grike or can occur as a complex of nested or connected feature types (Figure 6). An example might be a cave entrance located within a larger enclosing depression that also functions as a sink point for a sinking stream. In the latter case all three components of the nested/connected feature could be sampled if time available or just the karst depression that encloses the cave entrance and maybe the last segment of the sinking stream. Clusters of surface karst features such as sinkholes may only require sampling of one or two sinkholes rather than every sinkhole. A series of simple rules have been developed to address the different types of features and how best to select them for sampling.

4. Evaluation of Surface Karst Features - In this step the dimensions and other basic characteristics of the surface karst feature are recorded first, and then the condition of the feature is evaluated using the seven core disturbance indicator questions. For

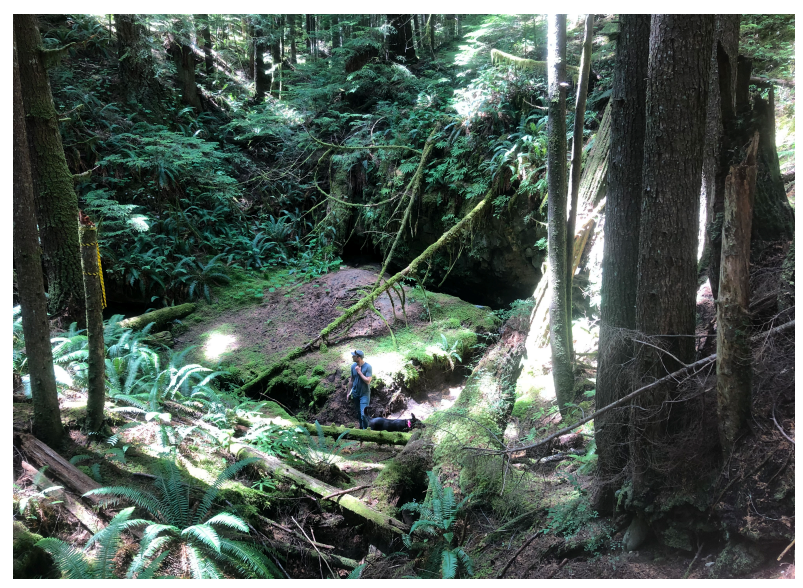

Figure 6. A complex surface karst feature in a second growth forest. The large sinkhole functions as a window with water emerging to right of image and sinking to left. 
example, with a sinkhole the plan view, shape, diameter and depth are recorded. A key part of this process is to determine the limits of the feature; for sinkholes this will be the rim (as defined by the slope break), while for cave entrances it will be the opening and/or dripline, except where the mouth or threshold of the cave entrance is enclosed by a sinkhole (in which case the limit of the sample is at the sinkhole rim). A 2 m-wide zone is added to the outside edge of features to account for some of the roots of large trees and discrepancies in determining the limits of the feature. Once measurements and characteristics of the surface karst feature have been recorded, the seven core indicator questions related to current forestry activities are applied ${ }^{1}$. The disturbance indicator questions asked at each of the surface karst feature includes: a) tree removal, b) postharvest windthrow, c) introduction of material (logging debris or road construction material), d) forest floor/soil/bedrock disturbance, e) burning, f) alteration of shade, and g) change in the lower plant community (Figures 7 and 8). These indicator questions are simply answered as a 'Yes' or 'No' response based on visual observations in the field, and then additional information is gathered on the extent and amount of these disturbances. A 'Yes' response to any of the indicator questions means that the surface karst feature has been disturbed ${ }^{2}$. Typically, ten or more surface karst features might be sampled in a single day. In some cases where background information on surface karst features is lacking for a selected sample area it may be necessary to search for features in the field. In this case the number of features evaluated in a day could be significantly less.

5. Cave Evaluations - The dark zones of caves are not entered as part of the FREP karst procedure but are evaluated by an office exercise based on existing information. This evaluation determines whether: a) the caves have been confirmed by a qualified person, b) the caves have been appropriately mapped, and c) if cave infiltration areas has been delineated for the ground surface above the caves.

1 . These biophysical indicator questions were field trialed extensively between 2003-2009 and in part come from other FREP evaluation procedures.

2 . Note, these disturbances are not necessarily independent of each other and it is anticipated that some duplication may occur.
6. Advanced Options - In certain situations, the Advanced Options of the FREP karst evaluation procedure can be used. For example, if treed retention areas surrounding surface karst features

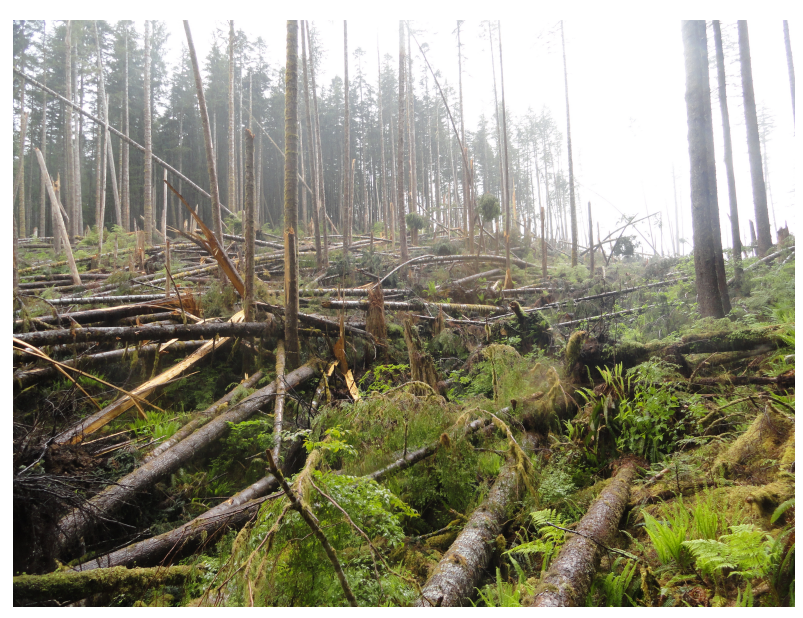

Figure 7. Area of disturbed sinkholes with windthrown/overturned trees and windsnapped trees.

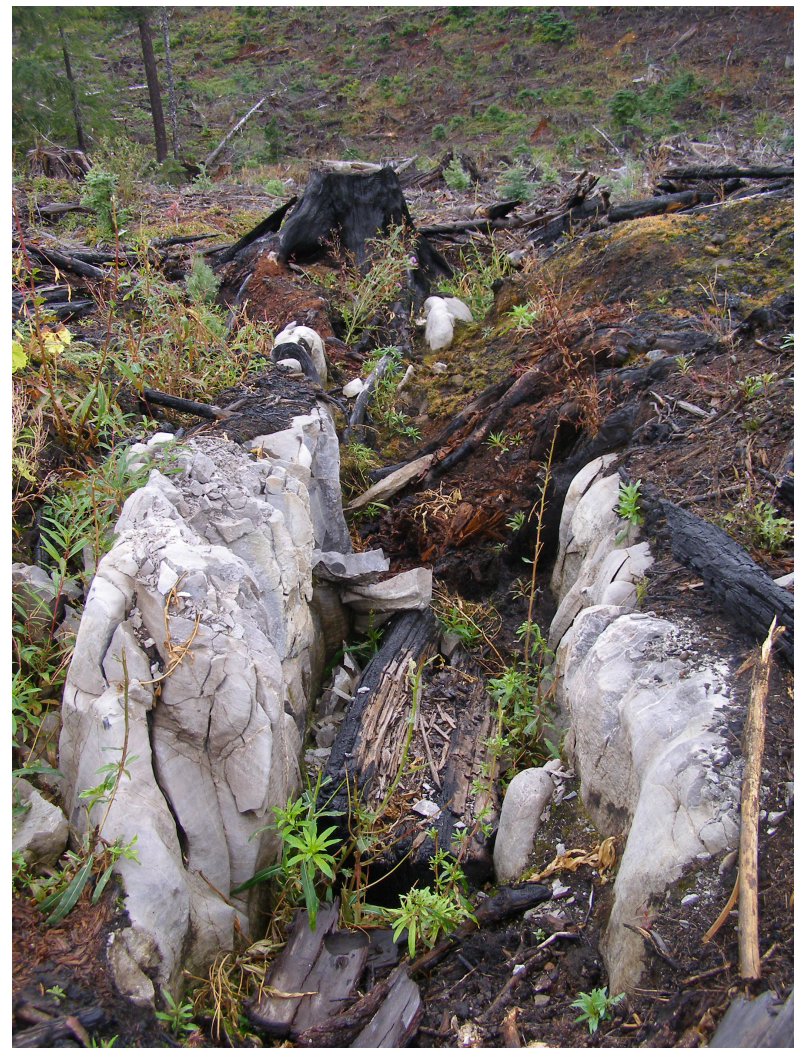

Figure 8. Soil and bedrock disturbance along edges of a large grike with burning and the introduction of logging debris. 
are consistently displaying evidence of post-harvest windthrow, there may be a desire to investigate these sites in more detail to measure the size of these retention areas and assess their disturbances. As another example, if a karst sample area has very few surface karst features (which can be the case) the nature of the broader karst landscape could be evaluated. In addition, if a cave infiltration area has been delineated for a cave, the extent of the area and any associated treed retention area could be examined and evaluated for disturbances.

7. Compilation of Results - Following the evaluation at a site it is then possible to compile the results and provide some preliminary analysis of the information gathered. The proportion of the disturbed versus undisturbed surface karst features is calculated, and the disturbances caused to features in harvested areas can be compared to those surrounded by reserves or treed retention areas. The procedure also provides information on the disturbed features in terms of the types of features disturbed, and the types of the disturbances. It should be noted, that a low number of disturbed features at a site does not necessarily imply less impact as this requires more in-depth consideration of the disturbances in terms of their type, direction (positive, neutral or negative), scale, scope, duration, as well as intensity/magnitude. At present there is no specific threshold of acceptable disturbance to surface karst features in BC. This requires more research and study of the ecological processes and responses of these features to disturbances. Therefore, the current approach is to assume that if no disturbance occurs to a surface karst feature then no adverse impact has occurred.

8. Closing Questions - At the end of the procedure the assessor is required to answer a series questions about the: sampling, karst data collected, forest practices and improvements to karst management at the site.

As part of evaluation procedure, a checklist has been developed to gather information on the selected sites/ cutblocks, the karst sample areas, the surface karst features, and the state or condition of the sampled features based on the responses to the disturbance indicator questions. This checklist has been complied into a digital format using Filemaker software and the data are gathered and analyzed using an Apple iPad. The benefit of this approach is that data collected in the field does not have to be transcribed, can be analyzed "on the go", and readily shared or saved to a database. Site photos can also be taken, and along with maps, stored digitally using the software. Typically, a hard copy checklist is kept on hand for use in the field if technical difficulties occur. Preliminary field testing of the digital check list has been carried out in a variety of field conditions. However, further testing and pilot training for assessors is anticipated for 2020, and feedback from this work will likely result in modifications. Research in the future will also help in further refining the procedure as it evolves over time.

\section{Conclusions}

A site level procedure has been developed for assessing disturbances to karst systems and their surface and subsurface elements following recent forestry activities. The focus of the procedure is to assess the state or condition of surface karst features using seven core disturbance indicators. The data are collected and analyzed in a digital checklist using Filemaker software and an Apple iPad. The information gathered on the number and proportion of disturbed surface karst features can then be used to determine improvements and/or modifications to forest practices in karst areas.

\section{Acknowledgements}

Development of the FREP evaluation procedure for karst has been ongoing for many years in BC. Paul Griffiths created some of the earlier versions and field cards in 2003-2009. Many others have contributed significantly to the field testing of these earlier versions and some of the later ones. The author has been involved in revising these earlier versions since 2015. Both Paul Griffiths and Christine Lohr (FLNRORD) should be particularly thanked for their useful feedback following review of this document.

\section{References}

Baichtal JF, Swanston DN. 1996. Karst landscapes and associated resources: a resource assessment. U.S. Department of Agriculture and Forest Service, Pacific N.W. Research Station, Portland, Oregon. General Technical Report PNW-GTR-383. 13 p

BC Ministry of Forests. 2003. Karst Management Handbook for British Columbia. Province of British Columbia, Victoria, BC. 81 p 
Day MJ. 1996. Conservation of karst in Belize. Journal of Cave and Karst Science 38 (2): 139144.

De Waele J. 2009. Evaluating disturbance on Mediterranean karst areas: the example of Sardinia (Italy). Environmental Geology 58: 239-255.

Drew D. 1996. Agriculturally induced environmental changes in the burren karst, Western Ireland. Environmental Geology 28: 137-144

Ford DC. 1993. Environmental change in karst areas. Environmental Geology 21 (3):107-109.

Ford DC, Williams P. 2007. Karst Hydrogeology and Geomorphology. Wiley. 562 p.

Forest Practices Board of BC. 2007. Protecting karst in Coastal BC. Forest Practice Board of BC, Special Report 31, Victoria, BC. 10 p

Forest Practices Board of BC. 2014. Management of Karst Feature Resource Features on Northern Vancouver Island. Forest Practice Board of BC, Special Report 31, Victoria. $22 \mathrm{p}$

Harding KA, Ford DC. 1993. Impacts of primary deforestation upon limestone slopes in northern Vancouver Island, British Columbia: Environmental Geology 21: 137-143.

Huntoon PW. 1992. Hydrogeologic characteristics and deforestation of the stone forest karst aquifers of south China. Ground Water 30: 167-176.

James JM. 1993. Burial and infilling of karst in Papua New Guinea by road erosion. Environmental Geology 21:114-151.

Jiang A, Lian Y, Qin X. 2014. Rocky desertification in Southwest China: Impacts causes and restoration. Earth Science Reviews 132: 1-12.

Kranjc. A. 2012. Dinaric Karst: An example of deforestation and desertification of limestone terrain. In: Maoutinho P, editor. Deforestation Around the World. InTech Publishing. p.73-94.

North LA, van Beynen PE, Parise M. 2009. Interregional comparison of karst disturbance: west-central Florida and southeast Italy. Journal of Environmental Management 90: 1770-1781.

Porte BL, North LA, Polk JS. 2016. Comparing and refining karst disturbance index methods through an application in an island karst setting. Environmental Management 58: 1027-1045.

Resources Information Standards Committee (RISC). January 2003. Karst Inventory Standards and Vulnerability Assessment Procedures for British Columbia (Version 2.0). Victoria, BC. 122 p.

Stokes, T. 2016. Preliminary analysis of surface karst feature data from Northern Vancouver Island. Forest Range and Practices Extension Note \#37. Victoria, BC. 7 p.

Stokes TR, Griffiths PA. 2109. An overview of karst areas in British Columbia, Canada. Geoscience Canada 46: 49-66.

Sunkar A. 2008. Deforestation and rocky desertification processes in Gunung Sewu karst landscape. Media Konservasi 13(3): 1-7.

Tissier G, Dzikowski M, Perrette Y. Poulenard J. 2013. Seasonal changes of organic matter quality and quantity at the outlet of a forested karst system (La Roche Saint Alban, French Alps). Journal of Hydrology 482: 139-148.

van Beynen PE. 2005. A disturbance Index for Karst. Environmental Management 36 (1): 101-116.

van Beynen PE. 2011. Karst Management. Springer. $489 \mathrm{p}$ 